\title{
Different effects of casein and soyabean protein on gastric emptying of protein and small intestinal transit after spontaneous feeding of diets in rats
}

\author{
BY HIROSHI HARA, HIROYUKI NISHIKAWA AND SHUHACHI KIRIYAMA \\ Laboratory of Nutritional Biochemistry, Department of Agricultural Chemistry, Faculty of \\ Agriculture, Hokkaido University, Sapporo 060, Japan
}

(Received 17 October 1990-Accepted I August 199I)

\begin{abstract}
The effects of dietary casein and soyabean-protein isolate (SPI) on gastric emptying and small intestinal transit were observed in rats fed on an $80 \mathrm{~g}$ casein or $80 \mathrm{~g} \mathrm{SPI} / \mathrm{kg}$ diet. After a $24 \mathrm{~h}$ fast, rats were given $2 \mathrm{~g}$ of both the test diets containing $10 \mathrm{~g}$ guanidinated casein $/ \mathrm{kg}$ diet as a marker protein. The amounts of the marker protein remaining in the stomach of the rats fed on the casein or SPI diet were similar and decreased to about $50 \%$ after $\mathbf{2 0}$ min. The emptying rate then slowed, especially in the casein group, so that the amount leaving the stomach after $1 \mathrm{~h}$ in the SPI group was slightly higher $(P<0.05)$. The small intestinal transit of chyme was estimated by a bolus injection of colloidal carbon suspension or of colloidal carbon and ${ }^{3} \mathrm{H}$-labelled polyethylene glycol through an implanted duodenal catheter 6 min before death. The average value of transit at 12, 20, 40 and $60 \mathrm{~min}$ after feeding of SPI diet was about $\mathbf{2 5} \%$ faster than that after casein diet. The transit velocity of the SPI group was also faster than that of the non-protein group $40 \mathrm{~min}$ after feeding. These findings reveal that SPI enhances the small intestinal transit of the liquid phase of chyme. There was no correlation between the gastric emptying of homoarginine and small intestinal transit. This result suggests that the small intestinal transit of lumen contents is controlled by the dietary protein regardless of the gastric emptying of protein.
\end{abstract}

Gastric emptying: Small intestinal transit: Dietary protein

Dietary protein has various effects on gastrointestinal functions; for example, digestive fluid secretion (Green et al. 1973) and gut motility (Daniel et al. 1990), both of which may affect the absorption rate of nutrients. Previously we reported that casein was absorbed much faster than soya-bean-protein isolate (SPI) and the absorption rates were markedly decreased 40 min after spontaneous feeding of diet containing both the proteins at a low level in conscious rats (Hara \& Kiriyama, 1991). The aim of the present study was to examine the effects of these proteins on gastric emptying and small intestinal transit under the physiological conditions adopted in the previous study.

The present study was designed to measure the gastric emptying of dietary protein and small intestinal transit of the liquid phase of chyme in the same rat during spontaneous feeding of a low-casein diet, a low-SPI diet, or a non-protein diet. Gastric emptying was observed using guanidinated casein as a marker in order to exclude the effect of endogenous proteins. Small intestinal transit was measured by a direct challenge of colloidal carbon suspension or of colloidal carbon and radiolabelled polyethylene glycol (PEG) through an implanted duodenum catheter (Summers et al. 1970).

EXPERIMENTAL METHODS

Gastric emptying was estimated using homoarginine (Expts 1 and 2), and small intestinal transit of the liquid phase was estimated as the 'leading edge' using carbon suspension 
Table 1. Composition $(\mathrm{g} / \mathrm{kg}$ diet) of diets

\begin{tabular}{|c|c|c|c|c|}
\hline Diet.. & $250 \mathrm{~g}$ Casein $/ \mathrm{kg}$ & $80 \mathrm{~g}$ Casein $/ \mathrm{kg}$ & $80 \mathrm{~g} \mathrm{SPI} / \mathrm{kg}$ & Non-protein \\
\hline Casein* & 250 & 94 & - & - \\
\hline SPI* & - & - & 96 & - \\
\hline Sucrose & 629 & 785 & 783 & 879 \\
\hline Maize oil $\dagger$ & 50 & 50 & 50 & 50 \\
\hline Minera! mixturet & 40 & 40 & 40 & 40 \\
\hline Vitamin mixture $\S$ & 10 & 10 & 10 & 10 \\
\hline Vitamin $\mathrm{E} \|$ & 1 & 1 & 1 & 1 \\
\hline Choline chloride & 20 & 20 & 20 & 20 \\
\hline
\end{tabular}

SPI, soya-bean-protein isolate.

* Nitrogen contents of casein and SPI were 137 and $134 \mathrm{~g} / \mathrm{kg}$ respectively, as evaluated by the Kjeldahl method.

$\dagger$ Retinyl palmitate $(7.66 \mu \mathrm{mol} / \mathrm{kg}$ diet $)$ and ergocalciferol $(0.0504 \mu \mathrm{mol} / \mathrm{kg}$ diet $)$ were added to the maize oil.

* The mineral mixture is identical to the mineral mixture 12 (MM2) described by Ebihara et al. (1979), providing (mg/ $\mathrm{kg}$ diet): calcium 4491 , phosphorus 2997 , potassium 3746 , magnesium 375 , iron 38.0 , iodine $0 \cdot 31$, manganese $81 \cdot 1$, zinc $25 \cdot 9$, copper $15 \cdot 3$, sodium 4342 , chlorine 6678 , selenium $0 \cdot 27$, molybdenum $1 \cdot 12$, chromium $0 \cdot 49$, bromine $0 \cdot 35$, vanadium $0 \cdot 22$, tin $1 \cdot 05$, arsenic $1 \cdot 20$, silicon $15 \cdot 7$, nickel $3 \cdot 00$, fluorine $2 \cdot 71$, cobalt $0 \cdot 20$.

$\$$ The vitamin mixture was prepared in accordance with AIN-76 mixture (American Institute of Nutrition, 1977) except vitamin $\mathrm{K}$ as menadione and L-ascorbic acid were added to give $5.81 \mu \mathrm{mol} / \mathrm{kg}$ (Bieri, 1977) and 284 $\mu \mathrm{mol} / \mathrm{kg}$ (Harper, 1959) diet respectively.

$\|$ Vitamin E (granulated, Yuvela; Eisai Co., Tokyo) supplied $423 \mu \mathrm{mol}$ DL- $\alpha$-tocopheryl acetate $/ \mathrm{kg}$ diet.

$\leftarrow$ Guanidinated casein $(10 \mathrm{~g} / \mathrm{kg}$; Expts 1 and 2) and $2 \mathrm{~g}$ indigo carmine $/ \mathrm{kg}$ (Expt 2) were added to both $80 \mathrm{~g}$ protein $/ \mathrm{kg}$ dicts for feeding.

(Expts 1, 2 and 3) and as the 'geometric centre' by radiolabelled PEG (Expt 3), and diet 'front' was estimated using indigo carmine (Expt 2).

\section{Diets}

Compositions of diets containing $(\mathrm{g} / \mathrm{kg}) 250$ casein, 80 casein, $80 \mathrm{SPI}$, and the non-protein diet are shown in Table 1 . Test diets were prepared by the addition of $10 \mathrm{~g}$ guanidinated casein $/ \mathrm{kg}$ and $2 \mathrm{~g}$ indigo carmine $/ \mathrm{kg}$ (only Expt 2) to an $80 \mathrm{~g}$ casein $/ \mathrm{kg}$ diet or an $80 \mathrm{~g}$ $\mathrm{SPI} / \mathrm{kg}$ diet in order to measure the gastric emptying rate and to estimate the diet 'front' in the small intestine respectively. Casein (ALACID; New Zealand Dairy Board, Wellington, New Zealand) and SPI (Fujipro R; Fuji Oil Co, Osaka) diets were made to contain $80 \mathrm{~g}$ net protein $/ \mathrm{kg}$ (where protein content was estimated as nitrogen $\times 6.25$ ), by adding either $94 \mathrm{~g}$ casein material or $96 \mathrm{~g}$ SPI material $/ \mathrm{kg}$, as shown in Table 1 . N contents of both materials were estimated by the Kjeldahl method. Indigo carmine (sodium indigotin disulphonate) was purchased from Wako Pure Chemical Industries (Osaka). Guanidinated casein, whose lysine residues were converted to homoarginine, was prepared by guanidination of $\epsilon$-amino groups in casein with 1-guanyl-3,5-dimethyl pyrazole nitrate (Habeeb, 1960) which was synthesized from aminoguanidine nitrate and acetylacetone (Wako Pure Chemical Industries). The conversion efficiency of lysine to homoarginine was $98 \%$.

\section{Animals and analyses}

Male Sprague-Dawley rats (Japan SLC Inc., Hamamatsu) were housed individually in separate cages. After a $24 \mathrm{~h}$ fast, rats weighing $220-240 \mathrm{~g}$ were anaesthetized by an intraperitoneal injection of pentobarbital sodium $(40 \mathrm{mg} / \mathrm{kg}$ body-weight; Abbott Co., North Chicago, USA). A duodenal catheter made of silicone tubing (Silascon No. 00; Dow Corning, Kanagawa; i.d. $0.5 \mathrm{~mm}$, o.d. $1 \mathrm{~mm}$ ), was implanted into the duodenum $10 \mathrm{~mm}$ distal to the pylorus and secured by a purse-string suture. The catheter was tunnelled 


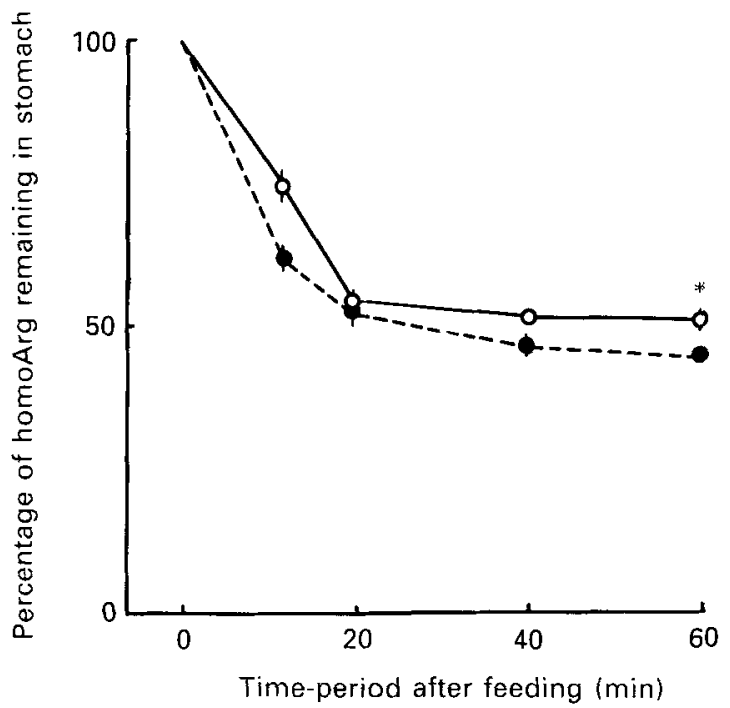

Fig. I. Gastric emptying of homoarginine in guanidinated casein after feeding an $80 \mathrm{~g}$ casein $/ \mathrm{kg}$ test diet $(O)$ or an $80 \mathrm{~g}$ soya-bean-protein isolate $(\mathrm{SPI}) / \mathrm{kg}$ test diet $(\boldsymbol{O})$. The values are means with their standard errors represented by vertical bars for six rats except $20 \mathrm{~min}$ in the casein group $(n 7)$ and the SPI group $(n$ 5). Mean values were significantly different from those for SPI group $\left({ }^{*} P<0.05\right)$. For details of diets, see Table I, and for details of procedures, see pp. 60-62.

subcutaneously to the back of neck. On the third day after implantation of the catheter we observed normal eating and growth, showing that the operative procedure did not interfere with the normal function of the gastrointestinal tract.

The rats were fed on a $250 \mathrm{~g}$ casein $/ \mathrm{kg}$ diet during the $10 \mathrm{~d}$ recovery period after surgery. After a $24 \mathrm{~h}$ fast, rats were given $2 \mathrm{~g}$ of the casein test diet, the SPI test diet, or the nonprotein diet. The rats were killed by decapitation at 20,40 and $60 \mathrm{~min}$ (Expt l) and $12 \mathrm{~min}$ (Expt 2) after feeding of the test diets. To measure the 'geometric centre' (Expt 3) rats were killed at $40 \mathrm{~min}$ after feeding. Carbon suspension in $10 \mu \mathrm{l}$ saline $(9 \mathrm{~g}$ sodium chloride $/ 1$;

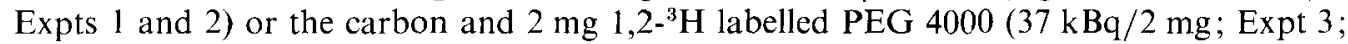
NEN Research Products, Boston, USA) in $30 \mu \mathrm{l}$ saline was given through the implanted duodenal catheter $6 \mathrm{~min}$ before the rats were killed to measure the small intestinal transit.

The pylorus, cardia, and terminal ileum were ligated, and the stomach and small intestine were immediately removed and clipped at the leading edge of the markers, and also clipped to divide the small intestine into eight segments of equal length. The length of the total small intestine and the distance the 'leading edge' of carbon (black) and indigo carmine (blue, Expt 2) had travelled from the pylorus were measured. To calculate the 'geometric centre' (Expt 3 ) the radioactivity in the eight segments of the small intestine was estimated without loss of contents.

The radioactivity was measured by a liquid-scintillation system (LSC-700, Aloka, Tokyo) after solubilization of each segment, including the contents, with Protosol (NEN Research Products). All gastric contents were collected and proteins and peptides were precipitated with trichloroacetic acid (TCA; $100 \mathrm{~g} / 1$ final concentration). After washing out TCA with diethyl ether, the proteins and peptides were hydrolysed by 6 M-hydrochloric acid $\left(110^{\circ}, 24 \mathrm{~h}\right)$ and the amino acids were analysed by high-performance liquid chromatography (HPLC) as phenyl thiocarbamyl (PTC) derivatives with phenyl isothiocyanate (Bidlingmeyer et al. 1984; Cohen et al. 1986) (Tokyo Kasei Kogyo). The 
HPLC was constructed from a Mini-Solvent Delivery System M-600 (Waters Assoc., Milford, USA) and PICO-TAG column $(15 \times 3.9 \mathrm{~mm}$, Waters Assoc.).

\section{Calculation and statistical analyses}

The gastric emptying of dietary protein was estimated as the homoarginine of guanidinated casein remaining in the stomach expressed as a percentage of the homoarginine given in the meal. The gastric emptying of the amino acids glutamic acid plus glutamine, proline, and leucine were also evaluated at the same time. Small intestinal transit was evaluated as the distance travelled in 6 min by the 'leading edge' of carbon expressed as a percentage of the total length of the small intestine, and as the 'geometric centre' of the labelled PEG. In Expt 2 we also estimated the distance the leading edge of chyme travelled in $12 \mathrm{~min}$ as a diet 'front' measured by indigo carmine.

The statistical analyses were performed by one-way and two-way ANOVA ('time' and 'diet'). Significant differences between means in Table 4 were determined by Duncan's multiple-range test. Linear regression analysis was performed between the gastric emptying of homoarginine and the small intestinal transit ('leading edge'). The significance of the correlation and the difference between means in Fig. 1, and Tables 2 and 3 were determined by Student's $t$ test.

\section{RESULTS}

The results of Expts 1 and 2 are combined and presented in Figs. 1 and 2, and Tables 2 and 3. As shown in Fig. 1, the percentage of homoarginine remaining in the stomach decreased to about $50 \%$ by $20 \mathrm{~min}$ after feeding of both casein and SPI test diets. The emptying rates of both the groups from 20 to $60 \mathrm{~min}$ slowed, especially in the casein-fed group. The percentage of homoarginine remaining was significantly lower in the SPI group at $60 \mathrm{~min}$.

The gastric emptying of the amino acids glutamic acid plus glutamine, proline, and leucine, which are mainly found in both casein and SPI, is shown in Fig. 2. The curves of these amino acids showed the same tendency as homoarginine, but there were no significant differences between the casein and SPI group at any time after feeding.

In Table 2, the transit of the intestinal chyme of the SPI group estimated by the 'leading edge' was faster than that of the casein group. The values at all time-points were almost the same within each group. The values of the transit at 40 and $60 \mathrm{~min}$ and overall for all four time-periods in the SPI group were significantly higher than those of the casein group. In contrast, the values of the diet 'front' at 12 min after feeding were similar in both the groups and the 'front' of both the groups had reached the lower ileum (Table 3).

Table 4 shows the values of the 'leading edge' and the 'geometric centre' estimated by PEG distribution in the small intestine at $40 \mathrm{~min}$ after feeding of both the casein and the SPI diet, and the non-protein diet as the control group. The faster transit rate of the SPI group compared with the casein group was recorded again, and the transit rate of the SPI group was also faster than that of the non-protein group, in both the indications of small intestinal transit. The correlation coefficient between the values of the 'leading edge' and that of the 'geometric centre' was $0.95(n 17, P<0.01)$.

Regression analyses were performed between gastric emptying and small intestinal transit ('leading edge'). There was no correlation. The correlation coefficients were 0.045 (n 12, not significant) and 0.137 ( $n$ 12, not significant) at 12 and 20 min respectively.

\section{DISCUSSION}

Guanidinated casein was used as a marker of gastric emptying of dietary protein in order to eliminate the effect of endogenous proteins. Rogers et al. (1960) reported that the changes in total $\mathrm{N}$ remaining in the stomach after feeding of a casein diet is almost the same 

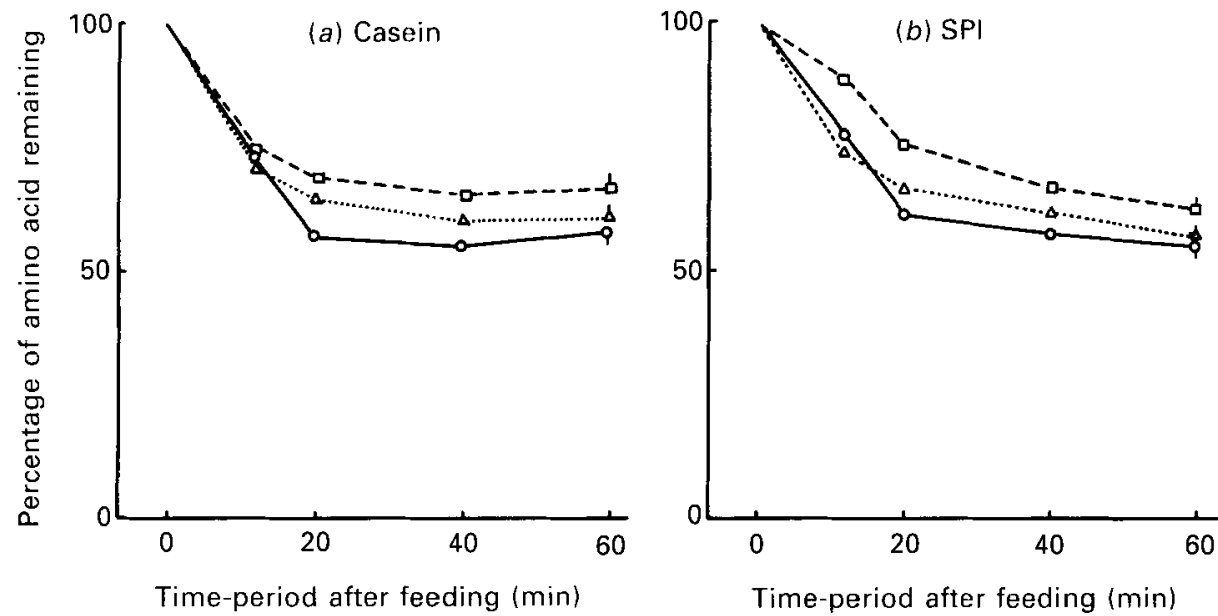

Fig. 2. Gastric emptying of glutamic acid plus glutamine $(O)$, proline $(\square)$ and leucine $(\triangle)$ after feeding $(a)$ an $80 \mathrm{~g}$ casein $/ \mathrm{kg}$ test diet or (b) an $80 \mathrm{~g}$ soya-bean-protein isolate (SPI) $/ \mathrm{kg}$ test diet. The values are means with their standard errors represented by vertical bars for six rats except $20 \mathrm{~min}$ in the casein group $(n 7)$ and the SPI group (n 5).

Table 2. Expts 1 and 2. Small intestinal transit of chyme $(\%) \dagger$ after feeding casein or soya-bean-protein isolate (SPI) test diets $\ddagger$ to rats $\$$

(Mean values with their standard errors for six rats except values for 20 min and 'All' which are shown in parentheses)

\begin{tabular}{|c|c|c|c|c|c|c|c|c|c|c|}
\hline \multirow{2}{*}{$\begin{array}{l}\text { Time-period after } \\
\text { feeding }(\min ) \ldots \\
\text { Diet }\end{array}$} & \multicolumn{2}{|c|}{12} & \multicolumn{2}{|c|}{20} & \multicolumn{2}{|c|}{40} & \multicolumn{2}{|c|}{60} & \multicolumn{2}{|c|}{ All $\|$} \\
\hline & Mean & $\mathrm{SE}$ & Mean & $\mathrm{SE}$ & Mean & $\mathrm{SE}$ & Mean & $\mathrm{SE}$ & Mean & $\mathrm{SE}$ \\
\hline $80 \mathrm{~g}$ Casein $/ \mathrm{kg}$ & $42 \cdot 9$ & $6 \cdot 2$ & $51 \cdot 3$ & $4 \cdot 6(7)$ & 46.6 & $2 \cdot 8$ & $5 ! \cdot 4$ & $2 \cdot 4$ & $48 \cdot 9$ & $2 \cdot 0(25)$ \\
\hline $80 \mathrm{~g} \mathrm{SPI} / \mathrm{kg}$ & $60 \cdot 1$ & $6 \cdot 1$ & $61 \cdot 5$ & $4 \cdot 7(5)$ & $59 \cdot 8 * *$ & $1 \cdot 7$ & $59 \cdot 4^{*}$ & $2 \cdot 2$ & $61 \cdot 8 * * *$ & $2 \cdot 1(23)$ \\
\hline
\end{tabular}

Mean values were significantly different from those for casein diet for the same time-perjod after feeding: $* P<0.05, * * P<0.005, * * * P<0.001)$.

$\dagger$ Distance travelled by the 'leading edge' of colloidal carbon in $6 \mathrm{~min}$ as a percentage of total length of the small intestine at 12, 20, 40 and $60 \mathrm{~min}$ after feeding (for details, see pp. 60-62).

\$ For details of diets, see Table 1

$\S$ For details of procedures, see pp. $60-62$

The overall sum of four time-periods.

as that after feeding a soya-bean-protein diet. Our results indicated that gastric emptying of protein in the casein group was significantly slower than that of the SPI group (Fig. 1). This finding provides evidence that the much faster absorption of casein compared with SPI (Hara \& Kiriyama, 1991), as described previously, was not due to the difference in gastric emptying. It was also observed that the profiles of gastric emptying of glutamic acid plus glutamine, proline, and leucine, which are mainly derived from dietary proteins, were similar to that of homoarginine (Fig. 2). These results indicate that the percentage of homoarginine remaining in the stomach gives a sensitive estimate of the gastric emptying of dietary protein.

The retardation of the discharge of dietary proteins from the stomach from 20 min to 60 min after feeding was also established. The marked decrease in absorption rate of protein 
Table 3. Expt 2. The diet 'front' (\%)* at 12 min after feeding of casein or soya-beanprotein isolate $(S P I)$ test diets $\dagger$ to rats $\ddagger$

(Mean values with their standard errors for six rats)

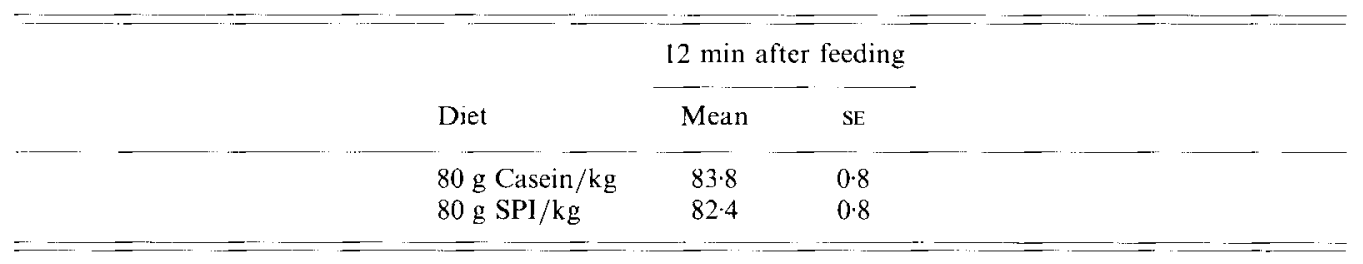

* Distance travelled by the leading edge of indigo carmine (blue dye) in 12 min as a percentage of the total length of small intestine.

+ For details of diets, see Table 1 .

\& For details of procedures, see pp. 60-62.

Table 4. Expt 3. Small intestinal transit estimated from the 'leading edge' (colloidal carbon) and the 'geometric centre' (radiolabelled polyethylene glycol (PEG))* after feeding casein or soya-bean-protein isolate (SPI) test diets $\dagger$ to rats

(Mcan values with their standard errors)

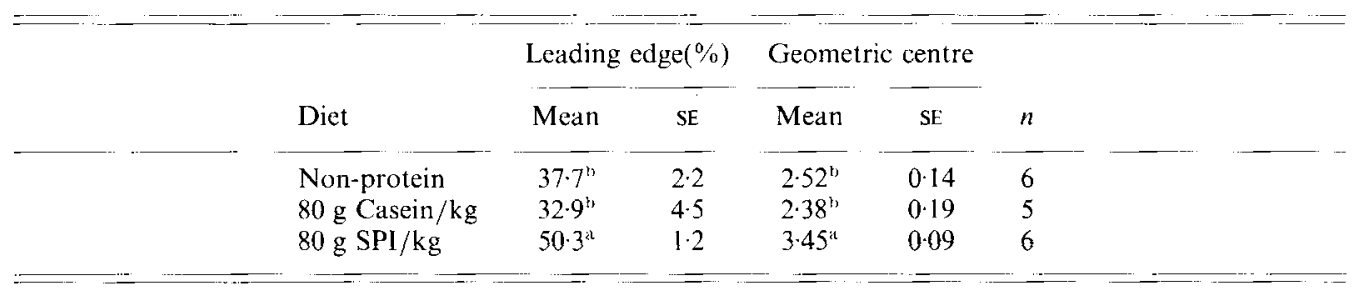

a,1) Mean values with unlike superscript letters were significantly different $(P<0.05)$.

* Estimated by an injection of carbon suspension (leading edge) or of ${ }^{3} \mathrm{H}$-labelled PEG (geometric centre, measured by the PEG distribution in eight segments) through the duodenal catheter 6 min before killing rats at 40 min after feeding of diets.

$\dagger$ The details of diets, see Table 1.

$\ddagger$ For details of procedures, see pp. 60-62.

in the early stages of feeding shown in our previous study (Hara \& Kiriyama, 1991) may have been due to the retardation of gastric emptying of protein. The reason for the retardation, especially in the casein group, even though more than $50 \%$ of the protein remained in the stomach, is not known (Fig. 1). The pattern of gastric emptying with two phases, fast and slow, observed in the present study agrees with several reported findings (Poulakos \& Kent, 1973; Mangel \& Koegel, 1984; Parr et al. 1988). Factors which affect gastric emptying are: particle size of gastric chyme, energy density and osmotic pressure in the duodenum (Hunt \& Knox, 1972; Burn-Murdoch et al. 1978), and gut hormone secretions. Two possibilities are considered for the retardation of emptying. First, both casein and soya-bean protein have a weakly acidic isoelectric point. Therefore, those proteins remaining in the stomach after 20 min may have comprised solid curds. Solid emptying is well known to be slower than liquid emptying. Secondly, dietary protein is known to be a stimulator of cholecystokinin release (Konturek et al. 1973; Liddle et al. 1986) and this hormone is known to slow gastric emptying (Debas et al. 1975; Moran \& McHugh, 1982; Mangel \& Koegel, 1984). Thus, the retardation of gastric emptying, especially in the casein group, may also be mediated by the release of cholecystokinin. 
Small intestinal transit of the SPI group is about $25 \%$ faster than that of the casein group, which may be related to the nature of the dietary protein itself because the same amount of protein travelled from the stomach up to $20 \mathrm{~min}$ after feeding (Fig. 1). Transit velocity of the small intestinal contents is generally determined by intestinal motility, fluid secretion into the lumen, viscosity of the chyme, and some amino acids in the lumen (Bull et al. 1985; Bouyssou et al. 1988). Opiates as well as several hormones control intestinal motility (Kinsman \& Read, 1984; Fioramonti et al. 1988; Kromer, 1988; Spiller et al. 1988). Soyabean protein may affect the secretion or action of hormones or opiates. Also, the slightly digestible peptides derived from SPI possibly exert the elevation of transit.

There was no difference in the diet 'front' between the casein and SPI group, as shown in Table 3. It suggests that the first chyme excreted from the pylorus moved along the small intestine at the same speed. The chyme indicates the pattern of dietary composition to the small intestine and sets the corresponding transit speed. This hypothesis was described by Schemann \& Ehrlein (1986). The other feature is that the transit velocity is decreased at the lower small intestine and the difference between diets in the proximal small intestine is reduced, which was demonstrated by Summers et al. (1970).

Gastric emptying and small intestinal transit were measured separately in the same rat. There are no correlations between gastric emptying and small intestinal transit while digesta is flowing copiously from the stomach, that is 12 and $20 \mathrm{~min}$ after feeding. These findings suggest that gastric emptying and small intestinal transit are controlled independently. Read et al. (1982) also report the same conclusion by different responses for gastric emptying and small bowel transit of various diets.

\section{REFERENCES}

American Institute of Nutrition (1977). Report of the American Institute of Nutrition ad hoc Committee on Standards for Nutritional Studies. Journal of Nutrition 107, 1340-1348.

Bieri, J. G. (1977). Second report of the ad hoc Committee on Standards for Nutritional Studies. Joumal of Nutrition 110,1726 .

Bidlingmeyer, B. A., Cohen, S. A. \& Tarvin, T. L. (1984). Rapid analysis of amino acids using pre-column derivatization. Journal of Chromatography 336, 93-104.

Bouyssou, T., Pairet, M., Candau, M. \& Ruckebusch, Y. (1988). Effects of intraluminal nutrients on intestinal myoelectric activity in rabbits. American Journal of Physiology 255, G12-G17.

Bull, J. S., Grundy, D. \& Scratcherd, T. (1985). The effect of intraluminal tryptophan and phenylalanine on small intestinal motility in the conscious dog. Journal of Physiology 367, 353-362.

Burn-Murdoch, R. A., Fisher, M. A. \& Hunt, J. N. (1978). The slowing of gastric emptying by proteins in test meals. Journal of Physiology 274, 477-485.

Cohen, S. A., Bidlingmeyer, B. A. \& Tarvin, T. L. (1986). PITC derivatives in amino acid analysis. Nature 320 , 769770

Daniel, H., Vohwinkel, M. \& Rehner, G. (1990). Effect of casein and $\beta$-casomorphins on gastrointestinal motility in rats. Journal of Nutrition 120, 252-257.

Debas, H. T., Farooq, O. \& Grossman, M. I. (1975). Inhibition of gastric emptying is a physiologic action of cholecystokinin. Gastroenterology 68, 1211-1217.

Ebihara, K., Imanura, Y.\& Kiriyama, S. (1979). Effect of dietary mineral composition on nutritional equivalency of amino acid mixtures and casein in rats. Journal of Nutrition 109, 2106-2116.

Fioramonti, J., Fargeas, M. J. \& Bueno, L. (1988). Involvement of endogenous opiates in regulation of gastric emptying of fat test meals in mice. American Journal of Physiology 255, G158-G161.

Green, G. M., Olds, B. A., Matthews, G. \& Lyman, R. L. (1973). Protein, as a regulator of pancreatic enzyme secretion in the rat. Proceedings of the Society for Experimental Biology and Medicine 142, 1162-1167.

Habeeb, A. F. S. A. (1960). A new reagent for guanidination of proteins. Canadian Journal of Biochemistry and Physiology 38, 493501.

Hara, H. \& Kiriyama, S. (1991). Absorptive behaviors of oligo-L-methionine and dietary proteins in a casein or soybean protein diet: observations by porto-venous difference in unrestrained rats. Journal of Nutrition 121 , 638-645.

Harper, A. E. (1959). Amino acid balance and imbalance. 1. Dietary level of protein and amino acid imbalance. Journal of Nutrition 68, 405-418.

Hunt, J. N. \& Knox, M. T. (1972). The slowing of gastric emptying by four strong acids and three weak acids. Journal of Physiology 222, 187-208. 
Kinsman, R. I. \& Read, N. W. (1984). Effect of naloxone on feedback regulation of small bowel transit by fat. Gastroenterology 87, 335-337.

Konturek, S. J., Radecki, T., Thor, P. \& Dembinski, A. (1973). Release of cholecystokinin by amino acids. Proceedings of the Society for Experimental Biology and Medicine 143, 305-309.

Kromer, W. (1988). Endogenous and exogenous opioids in the control of gastrointestinal motility and secretion. Pharmacological Reviews 40, 121-162.

Liddle, R. A., Green, G. M., Conrad, C. K. \& Williams, J. A. (1986). Proteins but not amino acids, carbohydrates, or fats stimulate cholecystokinin secretion in the rat. American Journal of Physiology 251, G243-G248.

Mangel, A. W. \& Koegel, A. (1984). Effects of peptides on gastric emptying. American Journal of Physiology 246 , G342-G345.

Moran, T. H. \& McHugh, P. R. (1982). Cholecystokinin suppresses food intake by inhibiting gastric emptying. American Journal of Physiology 242, R491-R497.

Parr, N. J., Grime, S., Critchley, M., Baxter, J. N. \& Mackie, C. R. (1988). Mechanisms governing the biphasic pattern of gastric emptying after truncal vagotomy and pyloroplasty. Gut 29, 1253-1257.

Poulakos, L. \& Kent, T. H. (1973). Gastric emptying and small intestinal propulsion in fed and fasted rats. Gastroenterology 64, 962-967.

Read, N. W., Cammack, J., Edwards, C. \& Holgate, A. M. (1982). Is the transit time of a meal through the small intestine related to the rate at which it leaves the stomach? Gut 23, 824-828.

Rogers, Q. R., Chen, M.-L., Peraino, C. \& Harper, A. E. (1960). Observations on protein digestion in vivo. III. Recovery of nitrogen from the stomach and small intestine at intervals after feeding diets containing different proteins. Journal of Nutrition 72, 331-339.

Schemann, M. \& Ehrlein, H.-J. (1986). Postprandial patterns of canine jejunal motility and transit of luminal contents. Gastroenterology 90, 991-1000.

Spiller, R. C., Trotman, I. F., Adrian, T. E., Bloom, S. R., Misiewicz, J. J. \& Silk, D. B. A. (1988). Further characterisation of the 'ileal brake' reflex in man - effect of ileal infusion of partial digests of fat, protein, and starch on jejunal motility and release of neurotensin, enteroglucagon, and peptide YY. Gut 29, 1042-1051.

Summers, R. W., Kent, T. H., \& Osborne, J. W. (1970). Effects of drugs, ileal obstruction, and irradiation on rat gastrointestinal propulsion. Gastroenterology 59, 731-739. 